\title{
Why Screening Rates Vary between Korea and Japan- Differences between Two National Healthcare Systems
}

\author{
Rei Goto ${ }^{1 *}$, Chisato Hamashima ${ }^{2}$, Sunghyun Mun $^{3}$, Won-Chul Lee ${ }^{4}$
}

\begin{abstract}
Both Japan and Korea provide population-based screening programs. However, screening rates are much higher in Korea than in Japan. To clarify the possible factors explaining the differences between these two countries, we analyzed the current status of the cancer screening and background healthcare systems. Populationbased cancer screening in Korea is coordinated well with social health insurance under a unified insurer system. In Japan, there are over 3,000 insurers and coordinating a comprehensive strategy for cancer screening promotion has been very difficult. The public healthcare system also has influence over cancer screening. In Korea, public healthcare does not cover a wide range of services. Almost free cancer screening and subsidization for medical cost for cancers detected in population-screening provides high incentive to participation. In Japan, on the other hand, a larger coverage of medical services, low co-payment, and a lenient medical audit enables people to have cancer screening under public health insurance as well as the broad range of cancer screening. The implementation of evidence-based cancer screening programs may be largely dependent on the background healthcare system. It is important to understand the impacts of each healthcare system as a whole and to match the characteristics of a particular health system when designing an efficient cancer screening system.
\end{abstract}

Keywords: cancer screening - screening rate - Japan - Korea - health insurance

Asian Pac J Cancer Prev, 16 (2), 395-400

\section{Introduction}

In many countries, population-based screening programs are implemented to reduce cancer incidence and mortality at the community level. Population-based screening is primarily differentiated from opportunistic screening in that invitations to target populations are issued from population registers (Miles et al., 2004). Moreover, governments have a certain responsibility for components of the screening, such as decisions about type of cancer and screening methods, eligibility decisions for the target population and providers, construction of a call-recall system, quality assurance, and budget.

In order to maximize the impact of cancer screening programs on population health, high screening rate is essential (Parkin et al., 2008). Both Japan and Korea provide population-based screening programs. However, there are many differences between the programs in these two countries. In 2010, the percentage of females screened for breast cancer among those aged 50 to 69 years was $36.4 \%$ in Japan and $63.6 \%$ in Korea, and for cervical cancer, the numbers were $37.7 \%$ in Japan and $63.8 \%$ in Korea. The difference in screening rates for cervical cancer has remained stable since 2004 when Korea began to provide comparable data to the Organization for Economic Co-operation and Development (OECD) (Organization for Economic Co-operation and Development(OECD) 2013). It is very important to understand why these differences exist.

There are many possible measures to increase screening rates. Review articles showed that interventions such as more personalized invitation methods, general practitioner involvement, and reduction of financial barriers (e.g., out of pocket payment and transportation) are effective at increasing screening rates (Vernon, 1997; Jepson and Martin-Hirsch 2002; Jepson et al., 2000; Everett et al., 2011; Forbes, Khalid-de Bakker et al., 2011). Differences in the implementation of these measures might explain large disparities in screening participation rates. However, to see the origins of these differences, it is also important to note that the underlying features of the healthcare system can be influential (International Agency for Research on Cancer 2002; Sabatino et al., 2012). Though both Japan and Korea have universal social health insurance systems, there are differences in the details of their health systems. These include the organization of insurers, the extent of centralization of different tiers of the government, coverage, and cost-containment mechanisms.

${ }^{1}$ The Hakubi Center of Advanced Research, Graduate School of Economic, Kyoto University, Kyoto, ${ }^{2}$ Cancer Screening Assessment and Management Division, Research Center for Cancer Prevention and Screening, National Cancer Center, Tokyo, Japan, ${ }^{3}$ Department of Business, Baekseok University, Cheonan, ${ }^{4}$ Department of Preventive Medicine, College of Medicine, The Catholic University of Korea, Seoul, Korea*For correspondence: goto.rei.7w@kyoto-u.ac.jp 


\section{Rei Goto et al}

This paper aimed to analyze the current status of the cancer screening and background healthcare systems in Japan and Korea and to elucidate the possible factors explaining the differences in screening rates between these two countries.

\section{Connections between Population-based Cancer Screening Health Insurance}

Table 1 shows an historical overview of populationbased screening systems in the two countries. In Japan, population-based cancer screening for gastric and cervical cancer started in 1983, 21 years after the realization of universal health insurance coverage. Lung, breast, and colorectal cancer screening were added to this program in 1998. Also in 1988, the budgetary responsibility of population-based screening was transferred from the central to local government during the process of decentralization.

There are about 3500 health insurance plans: roughly half are employee-based and half are community-based (Ikegami et al., 2011). Each local municipal government is the insurer for Citizens' Health Insurance, which is one of the community-based insurance plans. Under these plans, local governments simultaneously control cancer screening and health insurance. The National Health Insurance Association is a unified community-based insurance, which is a plan for employees and family members of small to medium-sized companies.

Employee-based insurance comprises societymanaged health insurance for large companies and Mutual Aid Associations for public sectors. For these plans, the governance of cancer screening and health insurance are separated.
In Korea, there were multiple insurers, both communityand employee-based, when universal coverage was established in 1989. These insurers were integrated into the National Health Insurance Corporation (NHIC) in 2000. The process of integration lasted until 2003, when the accounting system and premium collection integrated. The cancer screening program was expanded during the same time as detailed below (ref).

\section{Screening Delivery System}

In Japan, each insurer can provide their own cancer screening program for their beneficiaries under the Health Insurance Act. However, these screening programs cannot be categorized into population-based screening because the insurer (not the government) is the responsible party for the screening provision. The screening budget is the collective fund from the insured. Thus, there are at least two types of opportunistic screening in Japan: individual opportunistic screening, in which the person undergoing screening pays the whole cost; and collective opportunistic screening, in which health insurers provide a subsidy for their beneficiaries.

In Korea, the public cancer screening program was started only for public sector employees. In 1999, the National Cancer Screening Program (NCSP) was launched for the low-income population as a welfare policy. It is important to note that the unification of social health insurers was taking place concurrently. Prior to that, employee-based and community-based health insurance were operating independently and covered the entire population, like in Japan. Each insurer had its own independent screening program. During the unification, cancer screenings provided by different insurers were

Table 1. Historical Overview of Population-based Cancer Screening Systems

\begin{tabular}{|c|c|c|}
\hline Japan & Year & Korea \\
\hline Universal social health insurance coverage established & 1961 & \\
\hline $\begin{array}{l}\text { Population-based cancer screening governed and } \\
\text { sponsored by the central government launched: } \\
\text { gastric and cervical cancer screening }\end{array}$ & 1983 & \\
\hline \multirow[t]{3}{*}{ Expanded to include lung and breast cancer screening } & 1987 & \\
\hline & 1989 & Universal social health insurance coverage established \\
\hline & 1990 & $\begin{array}{l}\text { Cancer screening governed and sponsored by the central } \\
\text { government launched: only for public servants and teachers }\end{array}$ \\
\hline Expanded to include colorectal cancer screening & 1992 & \\
\hline \multirow{9}{*}{$\begin{array}{l}\text { Responsibility for the provision of cancer screening } \\
\text { was transferred from central to local government } \\
\text { (municipal level) }\end{array}$} & 1998 & \\
\hline & 1999 & $\begin{array}{l}\text { The National Cancer Screening Program (NCSP) launched for } \\
\text { people with low income: gastric, breast, and cervical cancer }\end{array}$ \\
\hline & 2000 & $\begin{array}{l}\text { Unification of public health insurers to single insurer, the } \\
\text { National Health Insurance Corporation (NHIC) }\end{array}$ \\
\hline & 2002 & $\begin{array}{l}\text { NCSP: target expanded to NHIC insured (whose insurance } \\
\text { premium is less than the 20th percentile) }\end{array}$ \\
\hline & 2003 & $\begin{array}{l}\text { Integration of an accounting system for insurers established } \\
\text { Target expanded to people whose insurance premium is less } \\
\text { than the } 30 \text { th percentile }\end{array}$ \\
\hline & & Expanded to include hepatic cancer screening \\
\hline & 2004 & Expanded to include colorectal cancer screening \\
\hline & & Financial support program for cancer patients started \\
\hline & 2005 & $\begin{array}{l}\text { Target expanded to people whose insurance premium is less } \\
\text { than the } 50^{\text {th }} \text { percentile }\end{array}$ \\
\hline
\end{tabular}


integrated into programs provided by the single insurer, the National Health Insurance Service (NHIC).

Currently, the NHIC provides the same cancer screening as the NCSP for those who are not eligible to be insured by the NCSP. The cancer screening provided by the NCSP and the NHIC is all the same program with tiny differences around available financial resources as described later. Thus, these two programs are operated as a single population-based program. Figure 1 shows a brief sketch of the Korean population-based screening system.

In Korea, large companies also provide an independent cancer-screening program using funds collected from the insured. Individuals can have free screening services paying total expenses. Thus, there are three types of cancer screening in Korea as well. Table 2 shows the different tiers of cancer screening in the two countries.

\section{Screening Program}

Table 3 shows the type of cancer, screening method, and screening interval. In Japan, the type, method, and interval have been recommended by a research group funded by a grant supported by the Ministry of Health, Labor, and Welfare (MHLW). This research group published evidence-based screening guidelines for each cancer type (Hamashima et al., 2008). These guidelines were not formulated by the Ministry and therefore are not mandatory. Thus, each municipality has final approval about these issues and the autonomy to decide whether or not to adhere to the guidelines.

\section{Table 2. Three Types of Cancer Screening in Japan and Korea}

\begin{tabular}{lll}
\hline \multicolumn{1}{c}{ Japan } & Type of cancer screening & \multicolumn{1}{c}{ Korea } \\
\hline *Municipal cancer screening program & Population-based screening & $\begin{array}{l}\text { *National Cancer Screening Program (NCSP) } \\
* \text { National Health Insurance Corporation } \\
\text { (NHIC) cancer screening program }\end{array}$ \\
*Cancer screening subsidized by insurers & & *Cancer screening subsidized by companies \\
*Optional cancer screening added to basic & Collective opportunistic \\
health check-up for the employed & & \\
*Cancer screening demanded by individuals & Individual opportunistic & *Cancer screening demanded by individuals \\
with full out-of-pocket & screening & with full out-of-pocket \\
*Cancer screening provided under health & & \\
insurance & & \\
\hline
\end{tabular}

Table 3. Type of Cancer, Screening Method, and Screening Interval

\begin{tabular}{|c|c|c|c|c|c|c|}
\hline \multicolumn{3}{|c|}{ Japan } & & \multicolumn{3}{|c|}{ Korea } \\
\hline Target Age & Screening Method & $\begin{array}{l}\text { Screening } \\
\text { Interval }\end{array}$ & & Target Age & Screening Method & $\begin{array}{l}\text { Screening } \\
\text { Interval }\end{array}$ \\
\hline 40 and over & Barium enema & 1 year & $\begin{array}{l}\text { Gastric } \\
\text { caner }\end{array}$ & 40 and over & $\begin{array}{l}\text { Barium enema or } \\
\text { upper endoscopy }\end{array}$ & 2 years \\
\hline 20 and over & Pap smear & 2 years & $\begin{array}{l}\text { Cervical } \\
\text { cancer }\end{array}$ & 30 and over & Pap smear & 2 years \\
\hline 40 and over & $\begin{array}{l}\text { Chest X-ray and } \\
\text { sputum cytology }\end{array}$ & 1 year & $\begin{array}{l}\text { Lung } \\
\text { cancer }\end{array}$ & Not Available & & \\
\hline 40 and over & $\begin{array}{l}\text { Breast examination } \\
\text { and mammography }\end{array}$ & 2 years & $\begin{array}{l}\text { Breast } \\
\text { cancer }\end{array}$ & 40 and over & Mammography & 2 years \\
\hline 40 and over & $\begin{array}{l}\text { Fecal occult blood } \\
\text { test (FOBT) }\end{array}$ & 1 year & $\begin{array}{l}\text { Colorectal } \\
\text { cancer }\end{array}$ & 50 and over & $\begin{array}{l}\text { Fecal occult blood } \\
\text { test (FOBT) }\end{array}$ & 1 year \\
\hline Not Available & & & $\begin{array}{l}\text { Hepatic } \\
\text { cancer }\end{array}$ & $\begin{array}{l}40 \text { and over } \\
\text { (only for those } \\
\text { with liver cirrhosis, } \\
\text { HBV/HCV positive } \\
\text { hepatitis) }\end{array}$ & $\begin{array}{l}\text { Abdominal ultrasono- } \\
\text { graphy and } \alpha \text { fetal- } \\
\text { protein }\end{array}$ & 1 year \\
\hline
\end{tabular}


Table 4. Financial Resources for Population-based Cancer Screening in Korea

\begin{tabular}{|c|c|c|c|c|c|c|}
\hline & \multirow[t]{2}{*}{ Target } & \multirow[t]{2}{*}{ Type of Cancer } & \multicolumn{4}{|c|}{ Financial Resources } \\
\hline & & & $\begin{array}{c}\text { Central } \\
\text { Government }\end{array}$ & $\begin{array}{c}\text { Local } \\
\text { Government }\end{array}$ & NHIC & Out-of-pocket \\
\hline \multirow[t]{3}{*}{ NCSP } & $\begin{array}{l}\text { Low income } \\
\text { (those exempted } \\
\text { from premium payment) }\end{array}$ & $\begin{array}{l}\text { Gastric, colorectal, } \\
\text { breast and cervical } \\
\text { cancer }\end{array}$ & $\begin{array}{c}50 \% \\
(30 \% \text { in Seoul) }\end{array}$ & $\begin{array}{c}50 \% \\
(30 \% \text { in Seoul) }\end{array}$ & $0 \%$ & $0 \%$ \\
\hline & $\begin{array}{l}\text { Those whose insurance } \\
\text { premium is less than the }\end{array}$ & $\begin{array}{l}\text { Gastric, colorectal, } \\
\text { and breast cancer }\end{array}$ & $\begin{array}{c}50 \% \\
(30 \% \text { in Seoul) }\end{array}$ & $\begin{array}{c}50 \% \\
(30 \% \text { in Seoul) }\end{array}$ & $90 \%$ & $0 \%$ \\
\hline & 50th percentile & Cervical cancer & $0 \%$ & $0 \%$ & $100 \%$ & $0 \%$ \\
\hline \multirow[t]{2}{*}{$\begin{array}{l}\text { NHIC Cancer } \\
\text { Screening }\end{array}$} & $\begin{array}{l}\text { Those whose insurance } \\
\text { premium is more than }\end{array}$ & $\begin{array}{l}\text { Gastric, colorectal, } \\
\text { and breast cancer }\end{array}$ & $0 \%$ & $0 \%$ & $90 \%$ & $10 \%$ \\
\hline & the $50^{\text {th }}$ percentile & Cervical cancer & $0 \%$ & $0 \%$ & $100 \%$ & $0 \%$ \\
\hline
\end{tabular}

care system. The NHIC created a list of objectives for the NCSP and the NHIC screening programs based on premium amounts for each individual. The NHIC sent invitation letters to participate in screening to all eligible residents. The demographic information of objective persons is stored in a database that can be accessed by the NHIC, regional health centers, and screening providers. This database is administered by the National Cancer Center. Regional health centers use this database to call people who were sent invitation letters and did not participate in screening to encourage them to do so.

The authentication of screening providers and quality management are mainly conducted by the National Cancer Center. The role of hospitals in providing screening services is larger than that of small clinics. Recently however, screening services have been expanded to include clinics in order to increase screening capacity.

In Japan, the ministry provides guidelines for evaluation of the municipal cancer screening program (Cancer screening committee Ministry of Health Labour and Welfare, 2007). The local municipalities contract with providers including hospitals, outpatient clinics, and both for- and non-profit organizations specializing in screening services. It is up to the local municipalities to monitor and maintain the quality of the screening performed by these various providers. However, the local municipalities only report macro-level data to the central government such as the number of participants screened, given a secondary examination, those with cancer detected, and the computed positive predictive value. The local municipalities do not monitor each provider at the micro-level.

\section{Available Financial Resources for Screening}

Table 4 depicts the payment allocation of populationbased cancer screening in Korea. Under the NCSP, the central or local governments assume the total screening cost for those with low income. For the other participants, the NHIC pays most of the cost as for the NHIC Cancer Screening. Eventually, there is no out-of-pocket payment for NCSP participants. Those with higher income have $10 \%$ out-of-pocket payment for gastric, colorectal, and breast cancer screening. This out-of-pocket payment is covered by central and local governments in the NCSP. The difference between the NCSP and NHIC Cancer Screening lies only in this payment allocation. Secondary examination after a positive screening result is also provided for free. Thus, population-based cancer screening is provided almost for free in Korea.

In Japan, each local municipal government can set the amount of out-of-pocket payment independently. The MHLW collected data on the content of examinations, strategies, and out-of-pocket costs for cancer screening among the different municipalities. According to this survey, the percentage of municipalities providing a free screening program is $8.3 \%$ for gastric cancer, $22.5 \%$ for lung cancer, $9.7 \%$ for colorectal cancer, $9.4 \%$ for cervical cancer, and $7.0 \%$ for breast cancer (Sano, Goto and Hamashima, 2014). Thus, most population-based screenings in Japan incur a financial burden on the participant being screened, which is rare in Korea.

\section{Available Financial Resources for Cancer Treatment}

According to the OECD health data, the percentage of gross domestic product (GDP) spent on healthcare in 2010 was $9.6 \%$ in Japan and $7.3 \%$ in Korea. In Japan, the government put a concerted effort toward cost containment via price control. The cost to payers is determined by a single-fee schedule. This single payment system has allowed total health care spending to be controlled despite a fee-for-service system with broad coverage of services and incentives to increase the volume of services (Ikegami and Anderson, 2012). The copayment rate is almost the same among different tiers of health care services. Generally, copayment rate is $30 \%$, and this is reduced to $10 \%$ for the elderly over 70 years old. In Korea, the government adopted a policy of limited benefit coverage under the NHI scheme with a high copayment for patients (Chun et al., 2009). The copayment rate ranges from $20 \%$ for inpatient care to $50 \%$ for outpatient care in general hospitals. In Korea, people often have to pay by themselves for services that are not covered by the NHI. In Japan, one cannot receive covered services and uncovered services at the same time in principle. Once a patient wants to have an uncovered service, they must pay the total cost of covered service as well as that of uncovered services. Private insurance benefits for uncovered services are not as common in Korea as in Japan. As a result, the percentage of out-of-pocket payment in the total health expenditure in 2010 was $34.2 \%$, which is much higher than in Japan (14.1\%).

Another important feature in Korean cancer screening 
is that there is a financial subsidy to medical treatment for those who are diagnosed with cancer in the NCSP. The subsidy is for out-of-pocket costs associated with cancer treatment covered by the NHIC, for a maximum of 3 years and a limit of 2 million won $(=2,000$ USD if 1 USD $=1,000$ won) per year. Those with high income are not eligible for the subsidy. Participants in the NCSP whose cancer is diagnosed by opportunistic cancer screening cannot have access to this subsidy program. The subsidy can provide a large incentive for those with lower income to participate in population-based screening as opposed to opportunistic screening where there is danger of a large financial burden for the individual.

\section{Coverage of Social Health Insurance}

In Japan, coverage of healthcare by public health insurance is broader than in Korea and physicians' autonomy for treatment choice is highly valued. Basically, preventive care for asymptomatic people is not covered in Japan. However, screening can be performed under public health insurance with low out-of-pocket cost, if the physician states a suspicion that the individual may have cancer even if the probability is about the same as the general population. Under the Japanese health insurance system, it is easy for asymptomatic individuals to receive healthcare services in an outpatient clinic identical to those provided in screening programs (Leung et al., 2008). An individual pays no more than $30 \%$ of the costs associated with such an examination and government insurance covers the rest. These patients usually see physicians regularly so additional transportation and time required are minimum.

In Korea, the Health Insurance Review and Assessment Service (HIRA), together with the NHIC, was founded to monitor medical claim data and provide quality assurance of NHIC health services (Park et al., 2012). Physicians generally hesitate to take risks to provide uncovered services because of this central audit system of medical claim data.

\section{Discussion}

In Japan and Korea, population-based cancer screening is provided for similar types of cancer and healthcare is managed under social health insurance. However, population-based cancer screening is managed differently in the two countries, which may explain the variance in screening rates between Japan and Korea.

Population-based cancer screening in Korea is coordinated well with social health insurance due to the centralized information system under the unified insurer. It is also operated along with the insurer's cancer screening program and together they cover the whole population. Unification of insurers drastically decreased the coordination cost between them. As a result, cancer screenings follow the country's cancer-control measures. In contrast, there are over 3000 insurers in Japan. The cost to coordinate cancer screening promotions between insurers can be very large.

One of the impacts that insurer unification can have on cancer screenings is clarification of the purpose of population-based screening. In Japan, many cancer screening programs are provided using a collective budget. Insurers can provide cancer screening programs independently and companies can add cancer screening to their basic health check-up items required for employees based on the Industrial Safety and Health Act. These are additional benefits for individuals and can be categorized as opportunistic cancer screening. These cancer screenings lack clear purpose, evidence-based management, and quality assurance. They do, however, use collective budgets unlike cancer screening with complete out-ofpocket payment. The decentralized nature of the Japanese healthcare system allows multiple opportunities for cancer screening. In Korea, companies independently provide financial support for cancer screening; but this is limited to employees of large companies.

The public healthcare system also has influence over cancer screenings. In Korea, public healthcare does not cover a wide range of services and it is common to have medical services that are only partially covered by public insurance. Low income households can get cancer screenings for free and their treatments will also be subsidized in case of cancer detection. This shows that cancer screenings are of the most social benefit to low income households. This reflects the fact that cancer screening services began by only covering low income households, and then expanded the eligible population based on impact on the budget. In Japan, on the other hand, a larger coverage of medical services, low co-payment, and a lenient medical audit enables people to have cancer screening under public health insurance as well as the broad range of cancer screening described above. For most people, screenings provided by insurance and populationbased screenings are the same.

Access to opportunistic screening is widely varied. In both countries, there are three types of cancer screening: population-based screening, collective opportunistic screening and individual opportunistic screening. In Korea, access to opportunistic screening is more limited than in Japan. Although some companies provide screening for their employees, Korean workers are facing greater instability of employment after the economic crisis in the 1990s and the average retirement age is younger than in Japan (Jung and Cheon, 2006). Even employees of large companies have to rely on one of two population-based screenings after retirement. For lower income Koreans, the NCSP is the only opportunity for affordable cancer screening. Meanwhile, there are many opportunities for cancer screening for all income levels in Japan. Both employee- and community-based insurers provide additional screening opportunities; municipal cancer screening is only one of them.

If we only examine cancer screenings, Korea seems more likely to provide well-managed service owing to the unified population-based screening. However, populationbased cancer screening plays a role to complement public health insurance with comparatively narrow coverage. On the other hand, Japan provides broad opportunities for cancer screenings. From the perspective of consumer sovereignty, it is reasonable if costs and benefits of 


\section{Rei Goto et al}

each individual screening are considered. However, it is inappropriate and inefficient resource allocation if screenings are performed with little scientific evidence of their necessity. There is only a few economic evaluations of cancer screenings for both countries (Sekiguchi et al. 2012; Shin et al. 2014). It needs more discussions about cost-effectiveness to realize the delivery of cancer screening efficiently

In Korea, most people choose population-based screening rather than opportunistic screening. Lee et al., estimated the gastric cancer screening rate from a sample survey by the National Cancer Center (Lee et al., 2010). The population-based screening rate for the bottom quartile of households in income increased from $23.9 \%$ in 2005 to $33.7 \%$ in 2009 , but the opportunistic screening rate decreased from $18.4 \%$ to $8.6 \%$ during the same time period. It is easy to infer that low income people switch from opportunistic screening to population-based screening because of large financial incentives. Moreover, the population-based screening rate for the top quartile households in income increased from $15.5 \%$ to $35.8 \%$ during the same period, but there was no significant change in the opportunistic screening rate $(23.9 \%$ to $24.8 \%$ ). This suggests that the overall increase in the population-based screening rate in Korea came from the shift of low-income households from opportunistic screening to populationbased screening as well as the overall increasing trend of participation to population-based screening.

In Japan, many measures have been taken to try to raise the screening rate. However, broad opportunities for cancer screening may lessen the impact of these measures targeted for population-based screening. The Japanese government began to send free vouchers to certain age groups. This policy might encourage these targeted populations to participate in population-based programs by publicizing the importance of cancer screening (Kuroki, 2012). However, if the screening service was already performed by the insurer, they may be reluctant to switch to population-based screening. It is important to formulate connections between population-based screening and screening programs provided by the insurer and to share information regarding evidence-based screening programs in the same fashion.

The implementation of evidence-based cancer screening programs may be largely dependent on the background healthcare system. A method that has shown to be successful in increasing the participation rate may not be effective in countries or regions with different health systems. It is important to understand the impacts of each healthcare system as a whole and to match the characteristics of a particular health system when designing an efficient cancer screening system.

\section{Acknowledgements}

This study was supported by the National Cancer Center, Tokyo, Japan (Grant number: 23-A-41). We thank Mr. Kakuho Furukawa for his research support. The authors have no competing interests to declare.

\section{References}

Chun CB, Kim SY, Lee JY, Lee SY (2009). Republic of Korea: health system review. Health Syst Trans, 11, 1-184.

Everett T, Bryant A, Griffin MF, et al (2011). Interventions targeted at women to encourage the uptake of cervical screening. Cochrane Database Syst Rev, 5, 2834.

Forbes C, Jepson R, Martin-Hirsch P (2002). Interventions targeted at women to encourage the uptake of cervical screening. Cochrane Database Syst Rev, 3, 2834.

Hamashima C, Saito H, Nakayama T, Nakayama T, Sobue $\mathrm{T}$ (2008). The standardized development method of the Japanese guidelines for cancer screening. Japanese J Clin Oncol, 38, 288-95.

Ikegami N, Anderson GF (2012). In Japan, all-payer rate setting under tight government control has proved to be an effective approach to containing costs. Health Affairs, 31, 1049-56.

Ikegami N, Yoo B-K, Hashimoto H, et al (2011). Japanese universal health coverage: evolution, achievements, and challenges. Lancet, 378, 1106-15.

International Agency for Research on Cancer (2002). Use of breast cancer screening. Pp. 47-86 in IARC handbook of cancer prevention breast cancer screening, edited by Harri Vainio and Franca Bianchini. Lyon, France: IARC press.

Jepson R, Clegg A, Forbes C, Lewis R, Sowden A (2000). Systematic review of the determinants of screening uptake and interventions for increasing uptake. Health Technology Assessment, 4, 133.

Jung, Ee-Hwan, Byung-You Cheon (2006). Economic crisis and changes in employment relations in Japan and Korea. Asian Survey, 46, 457-76.

Khalid-de Bakker C, Jonkers D, Smits K, et al (2011). Participation in colorectal cancer screening trials after first-time invitation: A systematic review. Endoscopy, 43, 1059-86.

Kuroki H (2012). Survey on the trends in uterine cervical cancer screening in Japanese women: The efficacy of free coupons in the screening. J Obstetrics Gynaecol Res, 38, 35-39.

Lee Hoo-Yeon, Eun-Cheol Park, Jae Kwan Jun, et al (2010). Trends in socioeconomic disparities in organized and opportunistic gastric cancer screening in Korea (2005-2009). Cancer Epidemiol Biomarkers Prev, 19, 1919-26.

Leung Wai K, Ming-Shiang Wu, Kakugawa Y, et al (2008). Screening for gastric cancer in Asia: current evidence and practice. Lancet Oncology, 9, 279-87.

Miles A, Cockburn J, Smith RA, Wardle J (2004). A perspective from countries using organized screening programs." Cancer, 101, 1201-13.

Organization for Economic Co-operation and Development. (2013). OECD Health Data 2013. Paris: OECD.

Park Y-T, Yoon J-S, Speedie SM, Yoon H, Lee J (2012). Health insurance claim review using information technologies. Healthc Inform Res, 18, 215-24.

Parkin DM, Tappenden P, Olsen AH, Patnick J, Sasieni P (2008). Predicting the impact of the screening programme for colorectal cancer in the UK. J Med Screening, 15, 163-74.

Sabatino SA, Lawrence B, Elder R, et al (2012). Effectiveness of interventions to increase screening for breast, cervical, and colorectal cancers: nine updated systematic reviews for the guide to community preventive services. Am J Prev Med, 43, 97-118.

Sano H, Goto R, Hamashima C (2014). What is the most effective strategy for improving the cancer screening rate? Asian Pac J Cancer Prev, 15, 2607-12.

Vernon SW (1997). Participation in colorectal cancer screening: a review. J Natl Cancer Inst, 89, 1406-22. 